\title{
0 tratamento dos fornecimentos conjuntos de vários bens, de vários serviços, ou de uma combinação de bens e serviços em sede do Imposto sobre o Valor Acrescentado europeu
}

\author{
Maria Odete Oliveira* \\ Universidade Lusófona do Porto
}

\author{
"When a man says he approves of something in \\ principle, it means he hasn't the slightest \\ intention of carrying it out in practice". \\ Otto von Bismarck
}

1. Introdução

Num artigo de 20 de Fevereiro de 2019, de Denise Lee Yohn, intitulado Why Great Innovation Needs Great Marketing, da Harvard Business Review', realça-se a importância, talvez hoje maior que nunca, das estratégias de marketing na definição do que vender, a quem vender e como vender, identificando as necessidades não atendidas e até desconhecidas dos clientes, entendendo os factores mais profundos das percepções e comportamentos relevantes para 0 apelo de um produto, interagindo com os clientes por meio de casos de uso e benefícios, em vez de funcionalidades e recursos, desenvolvendo todo o ecossistema de experiência do cliente e usando uma estratégia de entrada no mercado apropriada para a inovação e seu cliente.

* A Autora escreve segundo o antigo Acordo Ortográfico.

1. www.hbr.org 
ULP Law Review | Revista de Direito da ULP

Vol. 13, n. .1

doi:10.46294/ulplrv13n1d1

Citando Peter Drucker ${ }^{2}$, "Because its purpose is to create a customer, the business enterprise has two - and only these two - basic functions: marketing and innovation." ${ }^{\prime 3}$

Com as estratégias de marketing, o objectivo é, para a respectiva empresa, o de colocar 0 produto adequado no lugar certo, pelo preço adequado e no momento apropriado, 0 que requer um investimento considerável numa definição aparentemente simples. Um produto ou serviço promissor pode falhar totalmente e levar a perdas substanciais quando um dos elementos esteja errado.

Continuando, e sem pretensão de aprofundamentos que não sendo o objectivo deste estudo também estão fora do nosso conhecimento, cabe fazer referência a Borden ${ }^{4}$, e a o seu conceito de marketing mix, na esteira do qual o uso de um mix de marketing oferece uma excelente maneira de garantir que o produto certo seja colocado no lugar certo, mix que assim constituirá uma ferramenta ao serviço das empresas melhorando o seu conhecimento sobre o produto ou serviço que podem oferecer, com recurso a quatro elementos a saber: preço, produto, promoção e local (regra dos quatro P's - price, product, promotion and place $)^{5}$.

Os profissionais de marketing usam estas variáveis para estabelecer um plano de marketing, que reflita a melhor proposta para os consumidores de um mercado-alvo bem definido. A busca daquilo que a empresa pode fazer no sentido de influenciar a procura pelo seu produto, desenvolveu-se a um ritmo considerável passando pela oferta de bens e/ou serviços que combinem ou misturem diferentes tipos de funcionalidades.

\footnotetext{
${ }_{2}^{2}$ Peter Drucker foi um professor, consultor e escritor de origem austríaca, reconhecido, como um dos autores que mais contribuiu para as atuais teorias e práticas nas áreas de Marketing e Gestão de Empresas.

3 "Porque o seu objetivo é criar um cliente, a empresa possui duas - e somente essas duas - funçoes básicas: o marketing e a inovaçãa" - tradução nossa.

${ }^{4}$ Borden, N. H., The concept of the marketing mix (Journal of advertising research, 1964).

${ }^{5}$ Sem esquecer que cada elemento do mix de marketing contém infinitas alternativas e que das várias alternativas, a administração deve selecionar uma combinação de factores que vão satisfazer os mercados-alvo e atingir os objetivos de marketing e da organização
} 
ULP Law Review | Revista de Direito da ULP

Vol. 13, n. .1

doi:10.46294/ulplrv13n1d1

No âmbito de um imposto geral sobre o consumo como é o IVA (aqui o IVA comunitário) o problema relevante é o de saber qual a disciplina correcta a aplicar a esses fornecimentos ${ }^{6}$ que resultam da combinação de diferentes bens e/ou serviços.

Se 0 problema sempre se pôs neste imposto ${ }^{7}$, a temática ganhou ainda maior acuidade nos serviços electrónicos, prestados por sujeitos passivos a consumidores finais (não sujeitos passivos), as habitualmente conhecidas por operações B2C. Ou seja, sempre que no agrupamento ou "pacote" existam tipos diferentes de bens ou serviços, a definiç̧ão da respectiva disciplina tanto em termos de tributação versus isenção, de localização da operaçãa, ou das taxas aplicáveis à respectiva operação de fornecimento, resultam complexas e são susceptíveis de fomentar artifícios no sentido da busca de maior benefício, o mesmo é dizer de menor carga fiscal associada.

Reflectiremos sobre a temática dos fornecimentos conjuntos no desenvolvimento da abordagem. Ou seja, sobre como devem ser tratadas em sede de IVA as situações em que um ou mais bens e /ou serviços são vendidos juntos, tanto por um preço único como com separação de contraprestações.

\section{A temática}

Como imposto harmonizado que é, no espaço comunitário europeu, o caminho prosseguido desde que foi decidida a adopção do IVA como modelo geral de tributação do consumo, com as Primeira e Segunda Directivas, do Conselho, de 11 de Abril de 1967, até à actual e consolidada Directiva 2006/112, do Conselho, de 28 de Novembro de 2006, a sua disciplina sempre reflectiu essencialmente duas preocupações: adaptar a legislação às alterações que vão ocorrendo no mundo em geral e na economia em particular, e clarificar, interpretar e simplificar o cumprimento dos normativos que a integram, para além

\footnotetext{
${ }^{6} 0$ termo fornecimentos visa englobar tanto as transmissões de bens como as prestações de serviços, combinadas aquelas, estas, ou ambas.

${ }^{7}$ Realmente põe-se em qualquer tributaçãoo do consumo. Entre nós punha-se já no imposto em vigor até 1986 , o Imposto de Transacções.
} 
ULP Law Review | Revista de Direito da ULP

Vol. 13, n. .1

doi:10.46294/ulplrv13n1d1

obviamente da obrigatória resposta à abolição das fronteiras físicas (e fiscais) no mercado europeu.

Na tarefa de interpretação de conceitos ou situações em que a Directiva IVA não fornece solução certa e incontroversa, o Tribunal de Justiça da União Europeia (de futuro também e apenas Tribunal de Justiça ou Tribunal Europeu) tem um papel de relevante importância, como é sabido, através do estabelecimento de critérios sistemáticos e contextuais que, de forma coerente, assegurem às suas disposições consistência, uniformidade e menor ambiguidade, nomeadamente em termos de definição da incidência pessoal, incidência real, localização das operações, valor tributável ou isenções, que constituem os seus conceitos mais relevantes. E também critérios dinâmicos que não apenas identifiquem os termos autónomos no âmbito dos normativos da Diretiva IVA, mas que também os moldem nos objetivos, princípios e metas definidos nela, quer em termos funcionais (as normas devem ser interpretadas de tal maneira que funcionem efetivamente), quer em termos teleológicos (as normas devem ser interpretadas para alcançar os objetivos pretendidos) quer, finalmente, em termos de consequências (a interpretação da norma deve prever as consequências dessa interpretação).

0 caso específico dos fornecimentos conjuntos, compostos ou múltiplos, de futuro sempre referidos como fornecimentos conjuntos, de forma a que neles resultem incluídas tanto as transmissões de bens como as prestações de serviços, e que englobem as situações em que são transmitidos e/ou prestados, conjuntamente vários bens e/ou serviços, é um dos assuntos de grande complexidade à luz das disposições da Directiva IVA, tendo já dado origem a numerosos acórdãos do Tribunal de Justiça. A questão relevante é determinar se tais fornecimentos devem ser considerados como um único fornecimento ou antes como vários fornecimentos, reconhecendo a ausência de orientações claras na Diretiva IVA e as posições diferenciadas das várias autoridades fiscais e dos tribunais dos Estados Membros. Ora 0 Tribunal de Justiça tem, essencialmente nos últimos 10 anos, trazido alguma luz nesta área.

Vejamos com maior desenvolvimento a temática para depois concluir criticamente, não sem antes contrapor as realidades em análise, como bem se compreende. 
ULP Law Review | Revista de Direito da ULP

Vol. 13, n. .1

doi:10.46294/ulplrv13n1d1

Consideraremos, pois, na análise, fornecimentos únicos ou individuais quando um bem ou um serviço, perfeitamente definidos e individualizados, são transaccionados mediante um preço ou contraprestaçã̃o, e fornecimentos conjuntos quando o preço ou contraprestação paga ou a pagar tem associados vários elementos ou componentes, que podem ser a mistura de vários bens e /ou serviços ${ }^{8}$. Nestes últimos, pode acontecer que cada um dos itens, que são vendidos juntos por um determinado preço, possa ser fornecido independentemente por si só, ou a situação seja antes a de que cada parte do fornecimento se apresente, física e economicamente, dissociável das outras partes do mesmo, a significar que um dos elementos se apresenta como principal ou predominante, a par com um ou vários elementos acessórios, os quais, não seriam então susceptíveis de serem vendidos sozinhos sem 0 elemento principal.

\section{A análise na Directiva IVA}

Logo na Segunda Directiva IVA', de 11 de Abril de 1968, cujo artigo 2. ${ }^{\circ}$ foi depois retomado nos mesmos termos na Sexta Directiva IVA ${ }^{10}$, se consagravam como sujeitas a0 imposto sobre o valor acrescentado (IVA) as transmissões de bens e as prestações de serviços, efectuadas a título oneroso, no território do país, por um sujeito passivo agindo nessa qualidade e as importações de bens. Isto, num contexto que resultava já da Primeira Directiva ${ }^{11}$ com o respectivo artigo $2^{0}$ a estabelecer que "em cada transacção, o imposto sobre o valor acrescentado, calculado sobre o preço do bem ou do serviço à taxa aplicável ao referido bem ou serviço, é exigivel, com prévia dedução do montante do imposto sobre

\footnotetext{
${ }^{8}$ Fornecimentos compostos, múltiplos ou conjuntos, funcionam como um "pack" ou "pacote" que engloba vários elementos que existindo autonomamente podem também, ou devem até, ser transaccionados como um todo, podendo dessa forma serem objecto de condições diferentes de oferta, sejam de preço, desconto, ou outras. De fora ficam os bens e serviços que envolvendo, na sua criação diferentes elementos combinados, geram um bem ou serviço completamente novos.

${ }^{9}$ Directiva 67/228, do Conselho de 11 de Abril de 1967.

${ }^{10}$ Directiva 77/388/CEE, de 17 de Maio de 1977.

"Directiva 67/227, do Conselho de 11 de Abril de 1967.
} 
ULP Law Review | Revista de Direito da ULP

Vol. 13, n. .1

doi:10.46294/ulplrv13n1d1

o valor acrescentado que tenha incidido directamente sobre o custo dos diversos elementos constitutivos do preç,".

A actual Directiva 2006/112 (DIVA), que essencialmente consolida a Sexta Directiva em razão do regime transitório implementado em razão da abolição das fronteiras físicas e fiscais em 1 de Janeiro de 1993'2, retoma os mesmos termos na matéria que analisamos ${ }^{13}$.

Ou seja, o princípio subjacente à incidência do IVA nas transmissões de bens e prestações de serviços, é o de que cada transação deve ser considerada distinta e independente para efeitos de sujeição ao imposto. Em consequência, virá depois, para ela, a respectiva localização, o seu facto gerador e exigibilidade, a fruição ou não de uma isenção (outras que não as específicas do comércio internacional ou intracomunitário aqui não consideradas), 0 valor tributável, as taxas e obviamente, as questões conexas com 0 exercício do direito a dedução nos termos em o mesmo está consagrado.

Porque as Directiva IVA ligam transacção ao preço pago, o que é o normal num imposto sobre 0 consumo ou despesa, a doutrina sempre exigiu um "direct link" entre o pagamento e a correspondente transacção para que haja sujeição ao imposto. E o TJUE, num Processo de classificação de vários fornecimentos de serviços (que consistiam essencialmente em facilitar a troca, entre titulares do direito, de cada um ocupar uma casa de férias, com alguns pagamentos associados) e estabelecer a localização dos mesmos ${ }^{14}$, optou por determinar quais os pagamentos conexos com quais serviços, para então estabelecer os serviços que eram realmente fornecidos para efeitos do IVA. Ou seja, à decisão do Tribunal de Justiça subjaz o tratamento autónomo de cada transacção composta de um fornecimento e de uma contraprestação a ela ou com ela directamente ligada ou conexa.

\footnotetext{
${ }^{12}$ Directiva 2006/112/CE do Conselho, de 28 de Novembro de 2006. Como se diz no seu Considerando n. ${ }^{3}$, o objetivo essencial é "assegurar que as disposiçôes sejam apresentadas de forma clara e racional, em consonância com o princípio de legislar melhor".

${ }^{13}$ Arrigo 1. ${ }^{0}$ n. 2 : 0 principio do sistema comum do IVA consiste em aplicar aos bens e servicos um imposto geral sobre o consumo exactamente proporcional ao presco dos bens e servicos, seja qual for o número de operaçães ocorridas no processo de produção e de distribuição anterior ao estádio de tributaç̃ão.

Em cada operacãão, o IVA, calculado sobre o preşo do bem ou serviço à taxa aplicável ao referido bem ou serviço, é exigivel, com prévia dedução do montante do imposto que tenha incidido directamente sobre o custo dos diversos elementos constitutivos do preço.

${ }^{14}$ Processo RCI Europe contra Commissioners for Her Majesty's Revenue and Customs C-37/08, de 3 de Setembro de 2009, parágrafos 28-35.
} 
ULP Law Review | Revista de Direito da ULP

Vol. 13, n. .1

doi:10.46294/ulplrv13n1d1

A conclusão é então a de que quando uma transacção envolver múltiplas operações tributáveis ou sujeitas, mas que se apresentem como independentes, o princípio não pode ser outro que aquele que estabelece que cada uma delas seja tratada de modo independentemente para efeitos do imposto, em cada uma e todas as vertentes atrás referidas. 0 princípio é claro e, no geral, não levanta dificuldades de maior.

As dificuldades aparecem quando se aglutinam fornecimentos de bens e/ ou de serviços, em que não é possível concluir pela independência entre os mesmos. Exemplificação têmola, desde logo na disciplina das isenções (objectivas) nas operações internas, com destaque para serviços de interesse geral ${ }^{15}$, onde a letra dos normativos se direcciona para a abrangência não apenas de um específico serviço, mas também de outros serviç̧os ou bens, com aquele estreitamente conexos. Ou seja, parece estarmos perante operações conjuntas, em que será necessário determinar que elementos da transacção em referência qualificam ou não para efeitos da isenção por estarem estreitamente conexos ou se apresentarem com uma natureza meramente auxiliar em relação aos elementos (principais) que verdadeiramente relevam para a fundamentação da isenção. No contexto destas isenções, consideradas conceitos autónomos em IVA ${ }^{16}$, e com restritividade na sua interpretação para evitar de todo a violação do princípio fundamental da neutralidade do imposto, a temática de que tratamos apresenta-se complexa. Como bem realçava 0 Advogado Geral Jacobs ${ }^{17}$, as isenções e quaisquer limitações das mesmas devem ser interpretadas de forma a que a isenção se aplique àquilo que com ela se pretendia e a não mais do que isso.

Note-se ainda, a relevância da matéria também para efeitos das regras de localização da operação que são diferentes para fornecimentos de bens e de serviços, e nestes de serviços

\footnotetext{
${ }^{15}$ Nestas pontuam essencialmente a dos serviçç postais, prestação de serviços médico-sanitários, bens e serviços estreitamente conexos com serviços sociais por entes públicos ou organismos sem finalidade lucrativa, e alguns serviços culturais e educativos.

${ }^{16}$ Bobos-Rader, Daniel, "Os conceitos autónomos de direito da União Europeia na interpretação das normas de isenção do IVA", em Estudos em Homenagem ao Professor Doutor Alberto Xavier, Volume I, Coimbra, Almedina, 2013, pp. 291-313.

${ }^{17}$ A propósito do Processo (-267/00, Zoological Society of London, nas suas opiniōes de 13 de Dezembro de 2001
} 
ULP Law Review | Revista de Direito da ULP

Vol. 13, n. .9

doi:10.46294/ulplrv13n1d1

para serviç̧os, requerendo então qualificações mais específicas baseadas nas características

objectivas da transacção, dentro de cada categoria de fornecimento ${ }^{18}$.

Também em matéria de taxas ${ }^{19}$ a situação de agrupamento se pode colocar. Aqui, e não possuindo também tratamento expresso na Directiva, a temática apresenta, porém, em vários EM disciplina própria, como acontece entre nós com o artigo $18^{\circ}$ do Código do IVA cujo $n^{0} 4$ estabelece: "Nas transmissões de bens constituídos pelo agrupamento de várias mercadorias, formando um produto comercial distinto, aplicam-se as seguintes taxas:

a) Quando as mercadorias que compõem a unidade de venda não sofram alterações da sua natureza nem percam a sua individualidade, a taxa aplicável ao valor global das mercadorias é a que thes corresponder ou, se thes couberem taxas diferentes, a mais elevada;

b) Quando as mercadorias que compõem a unidade de venda sofram alterações $d a$ sua natureza e qualidade ou percam a sua individualidade, a taxa aplicável ao conjunto é a que, como tal, lhe corresponder".

\footnotetext{
${ }^{18}$ É excepcional o regime especial das agências de viagens e operadores de circuitos turísticos, aplicável a viagens e estadias na UE (os agentes de viagens que oferecem pacotes de viagens fora da UE estão isentos de IVA nessas operaçōes) quando tais prestadores de serviços actuarem perante o cliente em seu próprio nome (excluindo os casos em que os agentes turísticos actuam apenas como intermediários) mas recorrendo, para o fornecimento do pacote turístico, a bens ou serviços fornecidos por outras empresas (sujeitos passivos), operando o IVA por tributação da "margem" auferida, i.e. da diferença entre o custo dos serviços inclú́dos no pacote comercializado e a contraprestação recebida do cliente viajante. Aqui, e embora o pacote englobe um conjunto de serviços, a que poderiam ser aplicadas diferentes regras de sujeiç̧ão/tributação, localizaç̧̃o e taxas de imposto, o regime declara, com carácter obrigatório, que todas as transações incluídas no pacote turístico são tratadas como uma prestação de serviçços única, localizada no EM da UE em que se situe a sede ou estabelecimento do agente de viagens, Como salienta Terra and Kajus 2015a, p. 5058 "Whether the package includes services or goods that are normally subject to different VAT rules or rates, or only one service, is in principle irrelevant. This single supply under Article 307 is therefore often a fiction for VAT purposes.". E ainda como se decide no Processo Van Ginkel, C-163/91, parágrafos 13 e 14: "The services provided by these undertakings most frequently consist of multiple services, particularly as regards transport and accommodation, either within or outside the terition of the Member State in which the undertaking has established his business or has a fixed establishment.

The application of the normal rules on place of taxation, taxable amount and deduction of input tax would, by reason of the multiplicity of services and the places in which they are provided, entail practical difficulties for those undertakings of such a nature as to obstruct their operations

${ }^{19}$ De realçar que só no Processo Levob, o Tribunal de Justiça confirmou que a classificação como prestação composta é relevante para a aplicação das taxas de tributação $\left(n^{0} 18\right)$.
} 
ULP Law Review | Revista de Direito da ULP

Vol. 13, n. .1

doi:10.46294/ulplrv13n1d1

Contrariamente, nada se diz relativamente a um pacote de serviços, sendo certo que a situação se pode verificar no fornecimento conjunto de serviços à taxa geral de $23 \%$ e/ ou taxa reduzida de $8 \%$ e taxa intermédia $13 \%$.

Sobre estes acórdãos e outra jurisprudência do Tribunal Europeu de Justiça, tratar-se-á de seguida.

\section{A jurisprudência do Tribunal de Justiça}

Tem sido efectivamente o Tribunal de Justiça Europeu quem tem desenvolvido critérios para permitir a clarificação sobre quando uma transação conjunta (ou composta) deve constituir realmente uma única operação, e nesse caso qual o elemento ou elementos a qualificar como os relevantes, ou antes deverá a mesma ser entendida como um conjunto de transacções autónomas cada qual com o tratamento que especificamente lhe caiba.

0 processo habitualmente considerado como mais relevante na matéria de que tratamos é o Processo C-349/96 Card Protection Plan Ltd (CPP) contra Commissioners of Customs \& Excise Card Protection Plan, de 25 de Fevereiro de 1999, que ao que pensamos foi o primeiro sobre a matéria.

CPP vendia um pacote de serviços aos clientes (cartão de crédito), incluindo serviços de seguros (isentos ao abrigo do artigo 1351 a) da Directiva IVA) e um conjunto de outros envolvendo indemnização aos clientes contra perdas financeiras e outros prejuízos em caso de roubo ou perda dos cartões e fornecimento de outros apoios, sujeitos a efectiva tributação. As autoridades fiscais do Reino Unido qualificaram o CPP como um "pacote de serviços" comportando serviços de seguro, isentos, e outros, não isentos. E a questão posta ao Tribunal de Justiça foi essa mesmo, a de determinar se os vários serviços que integravam o plano de protecção do cartão de crédito deviam ser tratados como um fornecimento conjunto único ou, em vez disso, como vários e diferentes fornecimentos e, neste caso, quais os serviç̧os isentos e quais os que o não eram. 
ULP Law Review | Revista de Direito da ULP

Vol. 13, n. .1

doi:10.46294/ulplrv13n1d1

Na sua decisão, tendo por análise todos os factos e circunstâncias do caso que entendeu relevantes para ajuizar das características essenciais da transacção, 0 Tribunal tomou em conta, particularmente, o objectivo económico ou o fundamento económico da operação. Mas não só. Na fundamentação e análise o Tribunal realça e releva também o real interesse demonstrado pelo cliente individual, 0 motivo pelo qual este adquiriu o produto, i.e. a sua última e real intenção de compra, relevando aqui não a do cliente imediato mas sim a do consumidor final ${ }^{20}$.

Ou seja, do analisado se conclui que, para além da confirmação de que "toda prestação de um serviço deve normalmente ser considerada distinta e independente" e que os fornecimentos que constituem "um serviço único do ponto de vista económico não devem ser artificialmente divididos", sob pena de distorcer os princípios essenciais do sistema do IVA, os critérios fixados pelo TJUE demonstram que: a primeira determinação da natureza do serviço prestado ao cliente, definindo as "características essenciais da transação" deve ser tarefa dos tribunais nacionais; a análise deverá abranger todas as características objetivas e subjetivas das transações, não se restringindo apenas à variável preço que na equação não deve ter papel decisivo e naquela determinação e, perante fornecimentos conjuntos, deve ser definido se uma ou mais das suas componentes estão em posição de se qualificarem como fornecimento principal, enquanto outras componentes assumem natureza meramente auxiliar daquele fornecimento, assim devendo ser se não constituírem para os clientes um objetivo em si mesmos, mas tão só um meio de aproveitar melhor o serviço principal prestado", e sendo assim o tratamento a dar ao conjunto será o do serviço principal.

Durante largo tempo esta solução do CPPparecia apresentar-se como um procedimento claro e lógico para permitir soluções com relativa facilidade, embora sempre numa base casuística. № entanto, os litígios continuaram.

No Processo Levob Verzekeringen BV e OV Bank NV contra Staatssecretaris van Financiën (Levob), (- 41/04, de 27 de Outubro de 2005, a realidade factual era a seguinte:

\footnotetext{
${ }^{20}$ Teste utilizado pelo TJ em matéria de neutralidade para aferir se duas transacç̃oses ou bens são ou não similares do ponto de vista do consumidor final (Caso Rank Group, C-259/10), embora neste processo CPP formulado de forma mais detalhada e esquemática.
} 
ULP Law Review | Revista de Direito da ULP

Vol. 13, n. .1

doi:10.46294/ulplrv13n1d1

Levob, uma empresa de seguros holandesa, tinha contratado com uma empresa dos EUA $\left(\right.$ FDP $\left.^{21}\right)$ a aquisição de software personalizado ${ }^{22}$, a fim de comercializar os produtos de seguros para as companhias seguradoras dos EUA, estabelecendo o contrato que o FDP personalizaria 0 software básico por um preço separado e 0 instalaria e personalizaria nos sistemas da Levob. Levob importou a máquina com 0 software standard na Holanda e 0 fornecedor prestou os serviç̧os personalizados.

Levob considerou que o fornecimento de software normalizado incorporado num suporte informático constitui uma transmissão de bens na acepção do artigo $5^{0} n^{0} 1$ da Sexta Directiva. Só seria prestação de serviços o desenvolvimento do software especial adaptado às exigências do cliente.

As autoridades fiscais holandesas consideraram toda a transacção como um único fornecimento de serviços, o fornecimento de um software personalizado, integralmente tributável na Holanda, e do qual, após a respectiva liquidação do IVA por reverse charge Levob apenas podia deduzir uma pequena porção do IVA suportado e pago por esse serviço.

0 TJUE analisou se os elementos que integravam o contrato estavam "tão intimamente ligados que formavam objetivamente, do ponto de vista económico, uma só transação" ou não, comparando a compra do software em si mesmo com a relevância da personalização do mesmo software de forma a torná-lo útil para o comprador. Mais do que as condições de faturação e avaliaçãa dos diferentes elementos, foram considerados relevantes a respectiva natureza objetiva de um ponto de vista económico, já estabelecida, aliás, no CPP. Saber se se trata de elementos "tão intimamente ligados objetivamente, do ponto de vista económico, que devem entender-se como uma e toda uma transação" tornou-se tornou factor central na decisão. 0 TJUE concluiu que a base uniforme de apreciação prevista na Sexta Diretiva deve ser interpretada no sentido de que «quando dois ou mais elementos ou atos fornecidos por um sujeito passivo a um cliente, que seja um consumidor típico, estão tão intimamente ligados que formam objetivamente, do ponto de vista económico, uma transação que seria

\footnotetext{
${ }^{21}$ Financial Data Planning Corporation.

${ }^{22}$ A personalização incluía a tradução do programa em holandês e várias outras modificações assim como a formação do pessoal do comprador para o correcto uso do software. Eram cobrados preços separados para estas operações, nos termos do contrato.
} 
ULP Law Review | Revista de Direito da ULP

Vol. 13, n. .1

doi:10.46294/ulplrv13n1d1

artificial dividir, todos esses elementos ou atos constituem um fornecimento único para fins de aplicação do IVA. E isso é verdade para uma transação pela qual um sujeito passivo fornece um software padrão anteriormente desenvolvido e colocado no mercado e posteriormente personaliza esse software de acordo com os requisitos específicos do comprador, mesmo quando são pagos preços separados».

0 acórdão conclui afirmando que o fornecimento e posterior adaptação do programa informático devem, em princípio, ser qualificados como uma prestação única de serviços para efeitos de IVA, devendo 0 artigo $6 .^{\circ}$, n. ${ }^{\circ} 1$, da Sexta Diretiva 77/388 ser interpretado no sentido de que um único fornecimento deve ser classificado como um fornecimento de serviços, quando seja evidente que a personalização em questão não é acessória nem auxiliar, mas, pelo contrário, predomina; é esse o caso, em particular por ser de importância decisiva para permitir que 0 comprador use 0 suporte informático com 0 software personalizado.

Levob é fundamental na jurisprudência relativa a fornecimentos conjuntos: retomando, mas "afinando" os termos do Card Protection Plan. Nele, o Tribunal de Justiça definiu um agrupamento de actos como fornecimentos compostos admitindo a existência de uma categoria geral de fornecimentos compostos cujos elementos estejam economicamente integrados mas sem dominância de um elemento sobre outro. Assim:

- $\quad$ a venda de um produto (software gravado num suporte de dados) e o relacionado serviço de personalização do produto constituem um fornecimento único se a personalização não for meramente secundaria ou auxiliar, mas antes de importância decisiva;

a personalização é de importância decisiva se a sua extensão, custo, duração ou essa mesma personalização forem decisivas para permitir que 0 comprador use 0 produto para as suas necessidades específicas;

no caso de personalização de importância decisiva existe uma única prestação de serviços, mesmo que sejam estipulados preços 
ULP Law Review | Revista de Direito da ULP

Vol. 13, n. .1

doi:10.46294/ulplrv13n1d1

separados para a venda do produto (computador e respectivo software normalizado) e para a personalização do mesmo.

0 Processo C-251/05 Talacre Beach Caravan Sales Ltd contra Commissioners of Customs \& Excise apresenta natureza muito específica, o mesmo acontecendo com um outro Processo, o C-94/09, Comissão Europeia contra República Francesa, em que se discutia essencialmente, e no mesmo contexto, um problema de taxas aplicáveis a fornecimentos de bens.

Talacre vendia caravanas fixas (residenciais), novas e usadas, aplicando a ambos os fornecimentos uma taxa zero, aplicável no Reino Unido ${ }^{23}$. As caravanas vendidas incluíam, geralmente, casas de banho, revestimentos de chão, calhas para cortinados, cortinados, armários, cozinhas equipadas, assentos, mesas de jantar, cadeiras, bancos, mesas de café, espelhos, roupeiros, camas e colchões, sendo "propostas" aos clientes completamente montadas e mobiladas e não tendo estes qualquer influência sobre 0 respectivo equipamento. Nas facturas enviadas pelo fabricante das referidas caravanas à Talacre, eram indicados em separado o preço das caravanas sem IVA e o preço do respectivo equipamento interior acrescido de IVA à taxa normal.

A Talacre considerou, todavia, que a venda de uma caravana e do respectivo equipamento interior constituía um fornecimento único e indivisível, que, por conseguinte, deveria ser objecto de uma única taxa de tributação, concretamente, a aplicável ao elemento principal, a própria caravana. № caso a taxa zero.

As autoridades fiscais entenderam errado o procedimento e aplicaram a taxa zero apenas às próprias caravanas e a taxa normal do IVA ao respectivo equipamento interior, alegando que na derrogação que permitia a aplicação dessa taxa às caravanas se identificavam bens que não eram abrangidos pelo respectivo âmbito de aplicação (bens excluídos) pelo que 0 facto de a entrega ser única não impedia a exigência do imposto devido sobre a entrega dos bens excluídos.

\footnotetext{
${ }^{23}$ Taxa zero (isenção completa) autorizada ao Reino Unido com base no artigo 28. ${ }^{\circ}$ da Sexta Directiva.
} 
ULP Law Review | Revista de Direito da ULP

Vol. 13, n. .1

doi:10.46294/ulplrv13n1d1

A questão, reenviada ao TJUE, era se, usando os princípios de CPP, o fornecimento de uma caravana, com o seu integral e normal conteúdo interior deveria ou não ser tratado como um único fornecimento e beneficiar dessa isenção (taxa zero). Entendeu o mesmo não haver qualquer elemento que permitisse concluir que a tributação em separado de determinados elementos do fornecimento de caravanas equipadas envolveria dificuldades insuperáveis susceptíveis de afectar o bom funcionamento do regime do IVA e respondeu à questão colocada que o facto de determinados bens serem objecto de um fornecimento único (que inclui, por um lado, um bem principal abrangido, nos termos da legislação de um Estado-Membro, por uma taxa zero (isenção com reembolso do imposto pago na acepção do artigo 28. ${ }^{\circ} \mathrm{n}^{0}$ 2, alínea a), da Sexta Directiva) e, por outro, bens excluídos, pela referida legislação, do âmbito de aplicação dessa isenção), não impede o Estado-Membro em causa de cobrar o IVA à taxa normal sobre o fornecimento desses bens excluídos. A conclusão é pois no sentido da possibilidade de aplicar a um fornecimento conjunto duas (ou mais) taxas. Todavia, porque a temática é muito espeć́fica - a de aplicação excepcional de uma taxa zero, em condições especais na disciplina IVA ${ }^{24}$ - levantam-se dúvidas quanto à geral aplicação da disciplina que 0 acórdão consagra.

E a temática é retomada, mutatis mutandis, no outro Processo, o C-94/09 Comissão Europeia contra República Francesa.

A legislação francesa permitia a aplicação de uma taxa reduzida de IVA ao transporte de corpos de defuntos em veículos funerários. A Comissão Europeia argumentou que isso estava incorreto e que, embora a legislação da CE permitisse que uma taxa reduzida se aplicasse a esses serviços, ela deveria aplicar-se a todo 0 serviço funerário ${ }^{25}$. 0 Tribunal

\footnotetext{
${ }^{24}$ Tendo em conta a letra e o objectivo do artigo $28{ }^{\circ}$, n. $^{\circ}$ 2, alínea a), da Sexta Directiva, uma isenção nacional autorizada nos termos desse artigo só pode ser aplicada se estava em vigor em 1 de Janeiro de 1991 e se for necessária, segundo o Estado-Membro em causa, por razões de interesse social e em benefício dos consumidores finais. Ora, no caso em apreço, o Reino Unido da Grã-Bretanha e da Irlanda do Norte entendeu que só devia ser aplicada a taxa zero ao fornecimento das próprias caravanas, considerando que não se justificava aplicar igualmente essa taxa ao fornecimento do equipamento interior das referidas caravanas. ${ }^{25} \mathrm{~A}$ Comissão alega que 0 tratamento diferenciado das prestações de transporte de cadáveres em veículo é susceptível de introduzir distorções de concorrência, na medida em que as agências funerárias podem ser tentadas a aumentar artificialmente a parte do preço que declaram corresponder ao transporte de cadáveres em veículo, de modo a reduzir a parte do preço das outras prestações sujeita à taxa normal (parágrafo 43 do acórdão). Segundo a Comissão todas as prestações de serviços e entregas de bens realizadas pelas agências
} 
ULP Law Review | Revista de Direito da ULP

Vol. 13, n. .1

doi:10.46294/ulplrv13n1d1

Europeu constatou que na legislação francesa (não contestada pela Comissão), o transporte de cadáveres em veículo estava sujeito a regulamentação específica, apenas podendo ser feito por prestadores autorizados, em veículos especialmente preparados para esse efeito, sendo certo, como alegou a República Francesa, que esse mesmo transporte pode ser efectuado por um transportador autorizado, independentemente de qualquer prestação de serviços funerários. Declarou pois que a legislação francesa que sujeita o transporte de cadáveres em veículo a uma taxa reduzida de IVA cumpre os requisitos exigidos pela legislação da União nessa matéria distinguindo esta taxa da taxa aplicável aos serviços funerários. Idêntica conclusão e idênticas especificidades como em Talacre.

No Processo BGZ Leasing, C-224/11, BGZ Leasingera um empresa de locação financeira (leasing) polaca que, exigindo aos seus clientes, como condição para entrarem no contrato, que 0 locatário segurasse os respectivos activos, permitia a este tratar disso quer autonomamente quer através de serviço por ela prestado, situaçãa em que estabelecia um seguro com uma seguradora, e refacturava depois o custo desse seguro ao cliente.

As autoridades fiscais polacas classificaram essa actividade de seguro como acessória ou auxiliar do fornecimento principal, o leasing, e aplicaram IVA no refacturamento dos custos de seguro.

Foi pedido ao TJUE que se pronunciasse sobre se o elemento seguro era separadamente fornecido ou não.

Segundo o TJUE "como regra geral, um serviço de leasing e o fornecimento de um seguro para 0 item locado não podem ser vistos como estreitamente ligados a formar uma única transacção". Além de que "o facto de tratar tais fornecimentos separadamente não constitui em sim mesmo uma divisão artificial de uma transacção financeira única, capaz de distorcer o funcionamento do IVA". Continuando o raciocínio, considerou o Tribunal de Justiça que embora o seguro fornecido ao locatário através do locador facilitasse a fruição do serviço de locação financeira., o seguro devia ser considerado como constituindo um fim em si mesmo para 0 locatário e não um meio de fruir o serviço de leasing. E, o facto de que no caso do

funerárias às famílias dos defuntos constituem uma operação complexa única para efeitos de IVA, que, por consequência, deve ser sujeita a uma única taxa de imposto. 
ULP Law Review | Revista de Direito da ULP

Vol. 13, n. .1

doi:10.46294/ulplrv13n1d1

seguro cobrindo o elemento locado ser exigência do locador, não invalidou para 0 Tribunal a anterior conclusão negando a relação de acessoriedade, uma vez que o locatário tinha a opção de segurar o mesmo bem com uma companhia seguradora à sua escolha. Relevante foi ainda a consideração de que havia um preço e uma facturação separada, a reflectir os interesses das partes contratantes, com "0 locatário desejando acima de tudo obter serviços de leasing sendo o seguro fornecido pelo locador de importância secundaria para ele (decidindo o locatário que além do contrato de leasing queria também que the fossem fornecidos serviços de seguro através do locador, essa decisão é feita independentemente da decisão de efectuar um contrato de leasing"). Por fim o Tribunal realçou que as suas conclusões não podiam ser subvertidas por referencia ao artigo 78 da Directiva, que inclui os custos de seguro no valor tributável, já que neste caso a locação financeira constituía um fornecimento independente e um fim em si mesmo para o locatário, e os custos de seguro constituíam a contraprestaçãa para o fornecimento do seguro para o bem locado e não a contraprestação para o serviç̧o de leasing em si mesmo. A conclusão do TJ foi pois a de que, em regra um serviço de leasing e o fornecimento de seguro para 0 activo dado em locação financeira não podem ser vistos como estreitamente conexos de forma a constituírem uma única transacção. 0 facto de avaliar tais fornecimentos separadamente não deve constituir em si mesmo uma divisão artificial de uma operação financeira única susceptível de distorcer o funcionamento do sistema IVA, além de que em termos do princípio da neutralidade fiscal a escolha do comprador em obter o seguro do locador ou de outros prestadores deve conduzir ao mesmo tratamento.

Da jurisprudência analisada e de outra a que se fará referência quando caso disso, poderá considerar-se assente que a doutrina quanto a fornecimentos conjuntos tem uma regra principal, que é fácil e directa - considerar cada transacção como totalmente distinta e independente, com o tratamento IVA que the caiba, regra habitualmente denominada de "splitting" precisamente porque pede que cada um dos vários elementos que compõem uma transacção seja examinado de per sea partir das suas próprias características. A regra resulta directamente do princípio da singularidade constante do artigo 1 (2) segundo travessão da Directiva IVA, que estabelece que o IVA seja calculado sobre o preço final de todos os bens e 
ULP Law Review | Revista de Direito da ULP

Vol. 13, n. .1

doi:10.46294/ulplrv13n1d1

serviços fornecidos à taxa aplicável a esses bens ou serviços, devendo a liquidação ser relativa a cada transação (única transacção).

Como regra que é, o splitting comporta excepções a saber: dois ou mais fornecimentos devem ser tratados como um único e conjunto fornecimento se i) os mesmos constituem "um fornecimento único de um ponto de vista económico" ou ii) se um (ou alguns) dos fornecimento é (são) auxiliar(es) ou acessório(s) do outro considerado como principal. Um exame de ambas estas excepções é tratado a seguir.

Quanto à primeira excepção, pode dizer-se que não resulta totalmente claro, contudo, 0 que pretende o TJUE quando usa a expressão "de um ponto de vista económico" neste contexto - se a primazia deve ser atribuída ao fim "objectivo" económico da transacção ou se, em vez disso, é a intenção "subjectiva" demonstrada pelo cliente individual que deve, em primeiro lugar e antes de mais, ser tomada em consideração.

Aparentemente, em Aktiebolaget NN, C-111/05, o TJUE atribuiu primazia ao fim económico "objectivo" da transacção. Aktiebolaget NN instalava cabos de fibra óptica submersos e realizava testes operacionais depois de tal instalação. Nesta conexão, e para afastar a aplicação da regra principal sobre fornecimentos conjuntos i.e. a abordagem "splitting", o Tribunal considerou que "todos os elementos da transacção em apreço apareciam nos procedimentos principais como necessários à sua realização e, estavam estreitamente ligados. As conclusões do AG léger eram mais claras neste ponto. Ele fundamentava que "dado que o direito de dispor do cabo era apenas transferido quando a instalação estava completa e os testes operacionais tinham sido realizados, não estaria conforme à realidade económico-jurídica daquela transacção considerar que o cliente tinha primeiro comprado o cabo de fibra óptica submersa e subsequentemente os serviços relativos à instalação.

RLRE Tellmer Property, C-572/07, é outro Processo em que, aparentemente, o Tribunal adoptou uma abordagem objectiva para determinar o fim económico da transacção. Sobre a questão posta ao TJUE de saber se a facturação separada dos montantes para a limpeza das partes comuns de um edifício podia ser considerada acessória do aluguer ou arrendamento daquele edifício (isento de IVA), o Tribunal de Justiça entendeu que os serviços 
ULP Law Review | Revista de Direito da ULP

Vol. 13, n. .1

doi:10.46294/ulplrv13n1d1

de limpeza em questão não caíam necessariamente dentro do conceito de locação ou arrendamento da propriedade imóvel, com base em que, e apesar de tais serviços serem fornecidos pelo dono do edifício, esses serviços podiam, comercialmente, ser fornecidos por um terceiro directamente aos arrendatários, sem que o proprietário tivesse de estar envolvido.

A relevância de um padrão "subjectivo", a que olha para aquilo que um cliente individual, de um ponto de vista económico, pretende obter numa situaçãa específica, intenção "subjectiva" que, muito frequentemente, emerge dos termos contratuais entre as partes, encontra-se por exemplo em Field Fisher Waterhouse, (-392/11, respeitante a um contrato de arrendamento de escritórios por uma empresa de advogados, onde o TJUE decidiu que existia um fornecimento único de serviços entre o proprietário e o seu inquilino, na medida em que o contrato em questão exigia que, em adição ao arrendamento ou locação das instalações, o proprietário fornecesse ao inquilino (a empresa de advogados) um número de outros serviços e que a "razão económica" para o cliente individual (o inquilino) realizar 0 contrato não era meramente obter 0 direito de ocupar as instalaç̧ões, mas também 0 de receber esses outros serviç̧os.

0 mesmo em Régie Communale Autonome du Stade Luc Varenne, C-55/14. As cláusulas contratuais desempenharam também um papel decisivo para o TJUE concluir que a locação de um estádio de futebol, juntamente com o fornecimento de vários outros serviços, como manutenção, limpeza, reparação e melhoramento do edifício, não constituía, uma "locação de propriedade imobiliária", mas antes um fornecimento conjunto composto por vários serviços, dada a importância dada aos mesmos pelo adquirente, para assegurar que 0 estádio de futebol se adequasse ao uso a que era destinado, o de hospedar jogos de futebol. 0 valor económico dos serviços prestados que representava $80 \%$ do custo total acordado para 0 contrato constituía também um indício para qualificar 0 acordo em causa, no seu conjunto, como uma única prestação de serviços.

Linha similar de raciocínio no sentido da relevância subjectiva consta ainda da decisão do TJUE em Woiskowa Agencja Mieszkaniowa w Warszawie, (-42/14, processo relativo a uma empresa que cedia propriedade imobiliária juntamente com o fornecimento de determinadas "utilidades", incluindo electricidade, aquecimento, água e serviço de remoção 
ULP Law Review | Revista de Direito da ULP

Vol. 13, n. .1

doi:10.46294/ulplrv13n1d1

de lixo. De acordo com o acordo de locação entre as partes, a empresa cobrava aos inquilinos antecipadamente, usando a taxa de imposto especificamente aplicável a cada um dos serviços e, no fim de cada ano, ajustava os montantes cobrados de forma a reflectirem 0 consumo real desses serviços ou utilidades pelo respectivo cessionário ou inquilino. Considerando este modo de actuação, o TJUE decidiu que a circunstância de o "inquilino ser livre para determinar os seus próprios níveis de consumo" através da "existência de medidores e facturamentos individuais de cordo com 0 montante dos bens usados", implicava que o fornecimento das utilidades constituísse um fornecimento separado da locaçãa ${ }^{26}$. Ou seja, a capacidade de um cliente determinar o seu próprio nível de consumo, i.e. de fazer escolhas em relação aos produtos que the são fornecidos, é um factor de importância para conduir se há um único fornecimento composto ou não.

As duas abordagens supra, a "objectiva" e a "subjectiva", podem reconciliar-se na apreciação do objetivo económico direccionado ao consumidor "típico" ou "médio", evitando análises demasiado abstractas da operação económica ou, mesmo, arriscando "distinç̃ões artificiais baseadas em diferenças insignificantes". Aliás, já assim se procedeu Levob Verzekeringen and OV Bank com o TJUE, a decidir com base na assumpção de que os dois serviços em análise estavam tão estreitamente ligados que formavam, objectivamente, um único e indivisível fornecimento económico do ponto de vista de um "consumidor típico".

A segunda excepção à referida regra do "splitting", acima referida, respeita ao que pode ser designado como "princípio do auxiliar" ou "princípio da absorção" que, de forma breve, estabelecem que existe um único fornecimento (composto) se um ou mais elementos da

\footnotetext{
${ }_{26}$ "Dessa forma, num caso como o em causa no processo principal que, de acordo com os esclarecimentos apresentados durante a audiência, diz respeito à locação de um grande número de bens imóveis destinados a diferentes utilizacōes por um locatário, desde o hangar até à habitação, importa verificar se, no caso de cada locacacoan, no que respeita aos bens de base, o locatário é livre de decidir os seus consumos na quantidade desejada. A este respeito, a existência de contadores individuais e a faturacạ̃o em funç̃õo da quantidade dos bens utilizados é um indício importante que indica que se deve considerar que o fornecimento dos bens de base constitui prestacōes distintas da locaç̃õo. No que respeita ò gestão de residuos, se o locatário escolher o prestador ou puder concluir um contrato diretamente com ele, ainda que, por razões de facilidade, não exerça esta escolha ou faculdade, mas obtenha a prestação do operador indicado pelo locador com base num contrato concluído entre estes dois últimos, esta situação constitui um indício a favor da existência de uma prestação distinta da locação. Se, de resto, o montante devido a fítulo da gestão dos residuos e a título da locação aparecem em posiç̃ões diferentes na fatura, há que considerar que o locador não fornece uma prestação única que compreende a locacacão e a referida prestaç̃ão", parágrafo 45 do Acórdão.
} 
ULP Law Review | Revista de Direito da ULP

Vol. 13, n. .1

doi:10.46294/ulplrv13n1d1

transacção se qualificarem como o fornecimento principal, enquanto 0 outro ou outros assumem natureza de fornecimentos acessórios ou auxiliares, os quais, como tal, devem partilhar o tratamento do fornecimento principal. Em particular, um fornecimento deve ser visto como auxiliar de outro fornecimento principal se ele não constituir para um cliente um fim em si mesmo, mas simplesmente um meio de melhor fruir o fornecimento principal.

0 princípio do auxiliar constitui uma especificação do designado por "princípio da unidade do fornecimento" que exige que não se quebre uma transacção nas suas várias componentes, para aplicar o IVA separadamente a cada uma delas, mas antes se mantenha o foco no "todo" que o consumidor recebe. Este princípio é muito bem resumido na máxima latina accessorium sequitur principale uma regra que tem sido desenvolvida pelo TJUE em vários acórdãos na temática que nos ocupa e, aliás, em muitas outras áreas do direito comunitário. Talvez a melhor ilustração de uma situação em que um fornecimento deve ser olhado como auxiliar de outro fornecimento principal é quando exista uma conexão física entre os elementos dos dois fornecimentos, questão que já remonta a 1989, no Processo 173/88, Henriksen, em que o TJUE, chamado a pronunciar-se sobre se a "locação de instalações e espaços para parquear os veículos" que também incluía garagens fechadas conexas com propriedade imobiliária, cuja locação era isenta do IVA, respondeu a essa questão pela afirmativa baseado na conexão física existente entre as duas partes (os dois espaços).

É certo que considerar um fornecimento como auxiliar de um fornecimento principal exige uma análise casuística, que deve tomar em conta todos os factos e circunstâncias de um caso, 0 que por vezes está longe de ser linear, nomeadamente no respeitante a saber se a análise deve basear-se em aspectos qualitativos ou antes quantitativos. Em Madgett and Baldwin, C-94/97, o AG Léger faz referência a ambos os critérios qualitativo e quantitativo. Contudo, o método de contrapor estas duas abordagens, relativo à contribuição qualitativa ou quantitativa de um fornecimento para o todo da transacção económica, pode variar em cada situação específica. Uma abordagem predominantemente qualitativa foi feita pelo Tribunal em Purple Parking and Airparks Services, C-117/11, onde o TJ entendeu que os serviços relativos ao estacionamento de veículos num parque fora do aeroporto e transporte 
ULP Law Review | Revista de Direito da ULP

Vol. 13, n. .1

doi:10.46294/ulplrv13n1d1

de passageiros desses veículos entre o parque automóvel e o terminal do aeroporto constituía um fornecimento composto único, no qual o serviço de estacionamento era predominante, enquanto 0 serviço de transporte era meramente auxiliar a esse. Para chegar a uma tal conclusão, foi decisivo, inter alia, a observação de que "0 cliente procura, primeiro e antes de tudo, estacionar a um preço vantajoso", enquanto que o serviço de transporte é apenas a consequência inevitável do facto de que o parque automóvel está situado a certa distância do aeroporto, uma localização aceite pelo cliente dado que essa distância lhe permite pagar menos pelo serviço de parking.

Ainda um critério qualitativo, mas com referência específica ao modelo de negócio adoptado por um sujeito passivo, foi utilizado pelo TJUE em Mesto Zamberk, C-18/12. 0 Processo respeitava a uma companhia que operava um parque aquático, em que vários serviços aquáticos eram conjuntamente oferecidos aos clientes por um preço único de entrada. Embora a "reconstrução" factual última fosse deixada ao tribunal de envio, 0 TJUE concluiu que era feito um fornecimento composto único aos clientes, baseando-se na consideração que " o único tipo de bilhete de entrada oferecido pelo parque aquático dava acesso a todos os serviços, sem qualquer distinção conforme o tipo de serviço realmente utilizado e a maneira e a duração do respectivo uso durante o período de validade do bilhete de entrada" ${ }^{27}$.

Aparentemente, a abordagem relativa à contribuição qualitativa feita a uma operação económica como um todo é a preferida do TJUE, sem que uma abordagem quantitativa seja completamente desconsiderada pelo tribunal. Um critério quantitativo foi por ele adoptado em Régie Communale Autonome du Stade Luc Varenne, em que a circunstância de que 0 valor económico de certos serviç̧os representava $80 \%$ do valor económico da operação como

\footnotetext{
${ }^{27}$ Resulta da jurisprudênncia do Tribunal de Justiça que o elemento predominante deve ser determinado com base no ponto de vista do consumidor médio (v., neste sentido, designadamente, acórdãos Levob Verzekeringen e OV Bank, já referido, n. 22, e de 2 de dezembro de 2010, Everything Everywhere, (-276/09, Colet., p. 1-12359, n. 26) e tendo em conta, numa apreciação de conjunto, a importância qualitativa, e nõo simplesmente quantitativa, dos elementos abrangidos pela isenç̃õo prevista no artigo 132. n. I, alínea m), da diretiva IVA, relativamente aos que nõo estão abrangidos por essa isenção (v., neste sentido, acórdão Bog e o., já referido, n. 62) -parágrafo 30.
} 
ULP Law Review | Revista de Direito da ULP

Vol. 13, n. .1

doi:10.46294/ulplrv13n1d1

um todo conduziu o Tribunal a tratar esses serviços como 0 elemento principal daquilo, que em conjunto, era fornecido ao cliente.

E o preço atribuído a um serviço específico no contexto de um fornecimento conjunto também foi decisivo em $\mathrm{ISt}^{28}$, um caso em que uma empresa que oferecia aos clientes, em troca do pagamento de um montante global, serviços de viagens, formação linguística e serviços de educação. Aqui o TJUE fundamentou que, como a provisão dos serviços de viagens tinham um efeito substancial no preço total cobrado ao cliente, não representavam uma "parte marginal" em relação à formação linguística e serviços de educação Por isso não podia ser considerado como meramente auxiliar destes últimos serviços.

Mais recentemente, no Processo C-463/16 Stadion Amsterdam CV contra Staatsscretaris van Financiën, o TJUE confirma as suas posições anteriores

A Stadion Amsterdam é uma sociedade que explora um complexo imobiliário multifuncional denominado Arena, composto por um estádio e equipamentos conexos, incluindo o museu do clube de futebol AFC Ajax (a seguir «AFC Ajax») também instalado nesse complexo. Stadion Amsterdam arrenda 0 estádio a terceiros, para a realização de competições desportivas e, acessoriamente, para atuaç̧ões de artistas intérpretes. Além disso, oferece a possibilidade de visitar a Arena fora dos períodos de programação dos eventos desportivos ou musicais, no âmbito de visitas organizadas pagas, denominadas «World of Ajax», compostas por uma visita guiada ao estádio e uma visita, sem guia, ao museu do AFC Ajax. Nesse contexto, os participantes, acompanhados por um guia que thes transmite diversas informações sobre o AFC Ajax, o estádio e os espetáculos musicais, acedem à tribuna e ao terreno de jogo e vão à sala de imprensa e à sala de controlo do estádio. No final da visita guiada, os participantes têm a possibilidade de visitar livremente o museu do AFC $\operatorname{Ajax} x^{29}$

Entendendo que a visita organizada ao museu devia ser considerada uma prestação no domínio da cultura, ou uma atividade recreativa ou de lazer, a Stadion Amsterdam aplicou

\footnotetext{
${ }^{28}$ Finanzamt Heidelberg contra ISt internationale Sprach- und Studienreisen GmbH, C-200/04.

${ }^{29}$ No período em causa no processo principal, a saber, entre 1 de janeiro de 2001 e 30 de junho de 2005, não era possível visitar o referido museu sem fazer a visita guiada ao estádio.
} 
ULP Law Review | Revista de Direito da ULP

Vol. 13, n. .1

doi:10.46294/ulplrv13n1d1

a taxa reduzida de IVA prevista na sua legislação, sendo certo que na Holanda a entrada em museus é sujeita à taxa reduzida de 6\% enquanto que visitas ao estádio são tributadas à taxa normal de 21\%. Stadion baseava-se nas decisões Talacre e Comissão/França, de que sendo possível identificar "um elemento concreto e específico", no caso a visita ao museu, ele poderia ser sujeito, no fornecimento conjunto mas único, a uma específica.

Na sequência de uma inspeção tributária, a autoridade fiscal considerou que essa prestação devia ser sujeita à taxa normal de IVA. Em sede de recurso, o Supremo Tribunal, no seu acórdão, entendeu que uma visita organizada constituía uma prestação única que não podia ser dividida para efeitos da aplicação de uma taxa especial de IVA a uma das suas componentes, devendo as receitas recebidas como contrapartida das visitas organizadas ser submetidas, na íntegra, à taxa normal de IVA. Ou seja, a prestação de serviços em causa é composta por dois elementos: a visita guiada ao estádio e a visita ao museu do AFC Ajax, o primeiro dos quais constitui o elemento principal e o segundo, o elemento acessório, que dão assim lugar a uma prestação única.

0 reenvio ao Tribunal de Justiça tinha a seguinte questão prejudicial: «Deve 0 artigo 12. ${ }^{\circ}$ n. ${ }^{0}$, alínea a), da Sexta Diretiva ser interpretado no sentido de que, no caso de um serviço (que constitui uma única prestação para efeitos da tributação do IVA) ser composto por um ou mais elementos concretos e específicos (os quais, se considerados autonomamente, estarão sujeitos a diferentes taxas de IVA), a tributação do IVA do serviço composto deve ser feita em função das diferentes taxas aplicáveis a esses elementos assegurado que seja que o pagamento do serviço possa ser dividido segundo uma proporção correta desses elementos?»

Na sua decisão, o TJUE recusou a posiçãa da Stadion e considerou tratar-se de um fornecimento único militando os mesmos argumentos do CPP, sendo a sua divisão artificial e susceptível de distorcer o funcionamento do imposto. A operação deveria ser tributada como um todo à taxa aplicável ao elemento principal, a taxa de 21\%. 
ULP Law Review | Revista de Direito da ULP

Vol. 13, n. .1

doi:10.46294/ulplrv13n1d1

\section{Conclusões}

Embora tendo por objectivo o consumo final, como estabelecido pelo artigo 1 (2) segundo travessão da Directiva IVA, o IVA é administrativamente cobrado em cada transacção. A transacção é, de facto, 0 o pressuposto neste imposto.

Definir o que constitui exactamente uma transacção é por isso crucial, especialmente quando uma transacção é constituída pela provisão conjunta ao mesmo cliente de vários bens e/ou serviços, podendo até sê-lo por vários fornecedores ou prestadores, hipótese esta que aqui não analisamos, ficando para uma próxima análise.

A Directiva IVA não contém nenhuma norma ou conjunto de normas sobre a forma como fazer tal definição ou determinação. Algumas directrizes a este respeito têm todavia sido dadas pelo TJUE, o qual, através dos anos, e desde o Card Protection PLan, tem vindo a desenvolver uma específica doutrina sobre os fornecimentos conjuntos.

Como regra principal, o critério é o de que cada transacção deva ser considerada como totalmente distinta e independente. Excepções (a confirmar a regra) são os casos em que dois ou mais fornecimentos devem ser tratados como um fornecimento único e indivisível. Assim será se constituírem de um ponto de vista económico um fornecimento único ou se neles um dos fornecimentos for auxiliar do outro, o principal.

Para a primeira excepção se aplicar é relevante considerar que o fim económico "objectivo" de uma transacção bem como a intenção "subjectiva" demonstrada pelo cliente individual. No respeitante àquele, 0 modo pelo qual os serviços são apresentados no mercado, especialmente em termos da realidade e práticas comerciais, assume-se como factor de particular importância. Já no segundo, a intenção "subjectiva" do cliente individual, englobando a capacidade de um cliente determinar o seu próprio nível de consumo e fazer escolhas em relação aos produtos que lhe são fornecidos, circunstâncias que podem mesmo estar reflectidas nas disposições contratuais entre as partes, é factor determinante., As duas abordagens em análise podem eventualmente ser conciliadas quando o fim económico seja o do consumidor típico ou médio. 
ULP Law Review | Revista de Direito da ULP

Vol. 13, n. .1

doi:10.46294/ulplrv13n1d1

A segunda excepção, denominada de princípio do auxiliar ou da absorção, exige, na sua aplicação, que dois ou mais elementos de uma transacção constituam um fornecimento principal enquanto que outro ou outros constituam um fornecimento acessório ou auxiliar, de que resultará que este ou estes devem partilhar o tratamento do fornecimento principal. Nesta sede, deve um fornecimento deve ser considerado auxiliar de outro, o principal, se ele não constitui para o cliente um fim em si mesmo, mas simplesmente um meio de melhor fruir o fornecimento principal. Para assim ajuizar o TJUE refere habitualmente as contribuiç̧eses qualitativa e quantitativa de um fornecimento para a operação económica como um todo, embora, aparentemente, a preferência do TJUE seja baseada no aspecto qualitativo.

Em nossa opinião, e porque o contencioso é frequente, deveriam as instâncias comunitárias produzir uma posição interpretativa a partir das decisões jurisprudência do Tribunal de Justiça Europeu, mesmo que sem carácter vinculativo, mas para clarificar, simplificar e flexibilizar as actuações dos contribuintes, das autoridades fiscais e s tribunais, nacionais.

Essa necessidade foi, aliás, reconhecida pela própria Comissão, a vantagem de estabelecer algumas directrizes nesta matéria, no estudo Study on the Review of VAT Special Scheme for Travel Agents and Options for Reform ${ }^{30}$ onde são feitas propostas para desenvolver e tornar disponível, tanto para os EM como para os sujeitos passivos, directrizes detalhadas para determinar o melhor caminho para tratar a doutrina do TJUE sobre fornecimentos conjuntos. Nesse documento emitido quer pelo Comité IVA e Comissão, elencando-se as dificuldades face à limitação de conteúdos na Directiva IVA e à interpretação e aplicação dos critérios estabelecidos, numa base casuística, pelo Tribunal Europeu de Justiça, conclui-se assim:

It is necessary to look at the circumstances of individual transactions to determine which of the above approaches should be adopted. Therefore we do not make any judgment on which should be adopted and, where appropriate, consider the effects of each

\footnotetext{
${ }^{30}$ Study on the review of the VAT Special Scheme for travel agents and options for reform Final Report referido.
} 
ULP Law Review | Revista de Direito da ULP

Vol. 13, n. .1

doi:10.46294/ulplrv13n1d1

in the analysis that follows. We would note, however, that it would assist greatly in the achievement of a harmonised position if detailed guidance to be followed by all Member States and taxable persons could be made available (negrito nosso). ${ }^{31}$

Verdade é que, já a nível nacional alguns EM disponibilizaram algumas orientações a este respeito, enquanto que outros o não fizeram, e uma harmonização de critérios interpretativos resultaria muito vantajosa.

\footnotetext{
${ }^{31} E$ É necessário examinar as circunstâncias das transacōoes individuais para determinar quais das abordagens acima devem ser adotadas. Portanto, não fazemos nenhum julgamento sobre qual deve ser adotado e, quando apropriado, consideramos os efeitos de cada um na análise a seguir. Observamos, no entanto, que ajudaria muito na obtenção de uma posição harmonizada, caso houvesse orientaçōes detalhadas a serem seguidas por todos os Estados Membros e sujeitos passivos.
} 